\title{
A Study of a Hybrid Heat Pipe Solar Collector with an Absorber Plate
}

\author{
Nahin Tasmin", Abu Toib Salman, Rafiqul Alam Beg \\ Department of Mechanical Engineering, Rajshahi University of Engineering and Technology, Rajshahi, Bangladesh \\ Email address: \\ nahinarchi09@gmail.com (N. Tasmin) \\ ${ }^{*}$ Corresponding author

\section{To cite this article:} \\ Nahin Tasmin, Abu Toib Salman, Rafiqul Alam Beg. A study of a Hybrid Heat Pipe Solar Collector with an Absorber Plate. Advances in \\ Applied Sciences. Vol. 4, No. 6, 2019, pp. 110-119. doi: 10.11648/j.aas.20190406.12
}

Received: January 9, 2020; Accepted: January 20, 2020; Published: February 10, 2020

\begin{abstract}
Solar collectors have always been radical tools in the theoretical field of mechanical engineering as well as for any relevant establishment. Owing to uplifting demand for renewable energy sources, the investment for solar collector use is augmenting. Apart from flat plate or regular types, hybrid heat pipe solar collector could be taken for a neoteric type of solar collector. This research work aimed at designing and setting up a hybrid heat pipe solar collector and to evaluate the efficiency. A hollow copper pipe was used as heat pipe whose bottom end was closed by brazing a tiny solid copper block. Later the copper pipe was filled with acetone as the working fluid of heat pipe and by a burner, the bottom end of the pipe was heating until the pipe was filled with the vapor of acetone and then top of the pipe was closed by soldering. All other heat pipes, made of the same approach, were assembled then to an absorber plate touching the heat pipes forming the entire layout of heat pipe solar collector. The structure was then examined in the month of November and December and provided peak efficiency of about $27.44 \%$. The efficiency could be properly enhanced by further research and examination of the methodology of fabricating the heat pipes.
\end{abstract}

Keywords: Solar Collector, Heat Pipe, Acetone

\section{Introduction}

Non conventional source of energy is indisputably crucial to cope up with the rising energy crisis. Contemporary turbulent demand for energy is feeding mainly by non renewable conventional sources of energy like coal, gas, oil, petroleum that are not sufficient ad well as detrimental. Here comes the burning need to invest renewable energy sources such as solar, wind, geothermal or ocean energy. Furthermore from the Mechanical Engineering point of view two phase fluid flow, like within a heat pipe, is preferred than single phase, as it involves both laminar and turbulent flow characteristics. Hence the study of heat pipe has gained interests from heat transfer point of view. And mostly the benefit of phase change, namely the latent heat of evaporation and high heat flux densities were attractive to the designers of heat transfer equipment. [1] The objective of this project is to fabricate and construct heat pipe solar collector with an absorber plate and to evaluate its efficiency via a distinct as well as unprecedented working method.

\subsection{Principal Contents of the Project}

\subsubsection{Brief Mechanism of Heat Pipe Solar Collector}

Main fuel in this project is heat pipe solar collector whose utmost element is heat pipe generally of gravitational type. Simply it is an evaporating condensing device for rapid heat transfer. Perpetual cycle of condensation and evaporation is the very key process of a heat pipe using solar energy. A hollow casing or pipe and a suitable working fluid, are the radical contents of a heat pipe. Adequate amount of heat from sun or other external sources of heat, under characterizing pressure within the heat pipe, elevates the heat pipe's liquid to its boiling region. The working fluid in the heat pipe absorbs it's latent heat of vaporization with sun rays falling on it. The liquid releases its latent heat of vaporization in the condenser region, a box like structure made of thermally conductive material, namely header, where it comes into contact with the flowing colder liquid that will catch up the heat from the working fluid of the heat pipe. In this way the latent heat of vaporization is transferred. This 
process is repeated continuously by a gravity return feed mechanism of the condensed fluid back to the heat zone. [2]

\subsubsection{Scheme to Utilize Heat Pipe Solar Collector for Air Cooler}

These days one of the most knocked and clamoring concern of earth's environment is the ascending temperature. Articulately the usage of air cooler has taken its peak position to cope up with the standard of peoples' living. But the use of CFCs for refrigeration compression gives rise to global warming potential (GWP) and ozone depletion potential (ODP) which suppresses its further use as a refrigerant. [3] This is where the crucial significance of using environmentally friendly solar energy comes. An air cooler of regular type provides an amplified performance as well as efficiency when combining with a heat pipe solar collector installed after the compressor. Solar air cooler works alongside with the sun. During the heat of the summer days when conventional air coolers are struggling to cool and burning at least 3-4 amps per ton to do so, the solar collector on the solar air cooler is providing the energy necessary for the compressor operating between 1.5 to 2.5 of amps per ton as well as providing cooler and drier air.[4]

\subsection{Scopes of Solar Energy in Bangladesh}

This project was performed in Rajshahi city known as one of the summery regions of Bangladesh. Being an eminent source of renewable energy solar energy is accessible anywhere. But the greatest amount is available between two broad bands encircling the earth between $15^{\circ}$ and $35^{\circ}$ latitude north and south. Fortunately, Bangladesh is situated in between $20^{\circ} 43^{\prime}$ north and $26^{\circ} 38^{\prime}$ north latitude and as so this country is in a very favorable position in respect to the utilization of solar energy. Yearly amount of radiation fluctuates in between 1840 to $1575 \mathrm{kWh}$ per meter which is $50-100 \%$ higher than in Europe. Taking an average solar radiation of $1900 \mathrm{kWh}$ per square meter, total annual solar radiation in Bangladesh is equivalent to $1010 \mathrm{X} 1018 \mathrm{~J}$. Currently per year about $700 \mathrm{X} 1018 \mathrm{~J}$ amount of energy is being consummated in total which shows even if $0.07 \%$ of the incident radiation can be utilized, total requirement of energy in the country can be met. [5]

\section{Engineering Concept and Relevant Theory}

\subsection{Radical Theoretical Postulation of Heat Pipe}

\subsubsection{Concept of Heat Pipe Scheme}

A heat pipe is very simply a tubular device that is very effective in transferring heat, consists mainly of a metal container (aluminum, copper, etc.) that holds a liquid (water, acetone, etc.) as working fluid inside the tube. On the application of heat from some external source to the outer area of the tube, the working liquid boils and vaporizes into a gas. This gas then moves through the tube seeking a condenser that is a cooler location where it condenses.[6] As large quantities of heat can be transferred through relatively small cross-sectional areas with very small temperature differences, the heat pipe can be considered as an innovative engineering structure.[7] It also possesses high thermal conductance and low thermal impedance. From the figure of a heat pipe scheme it is seen that the cold liquid is evaporated at the heat source and the hot vapor flow is afterwards transported to the heat sink where the vapor condensates again and is transported back to the heat source.[8]

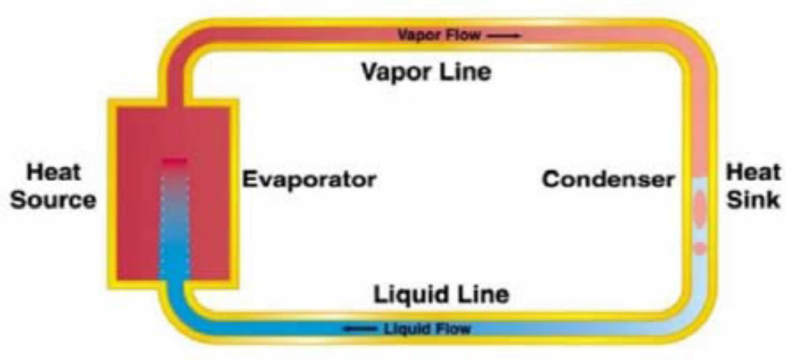

Figure 1. A heat pipe scheme.

\subsubsection{Contents and Types of Heat Pipes}

i. Types of Heat Pipes based on Working Principle

There exist varieties of heat pipes and all of them have some discrete parts depending on their types. Elementary type of heat pipe contains merely two main parts namely the container (the body) and the working fluid. A capillary structure known as wick can be set inside the heat pipe body to allow the condensed liquid phase of the working fluid wicking against the vapor flow as a result of capillary action. Heat pipe of this kind is called a wick heat pipe. There is another type of heat pipe without this wick structure and is called gravitational heat pipe. The working fluid in liquid phase returns from the condenser zone to the evaporator zone by gravitational force. [9] For this project gravitational heat pipe has been used.

ii. Cardinal Parts of a Heat Pipe

a) Container

The container of a heat pipe is a very cardinal part which is mainly a hollow metallic pipe containing the working liquid to produce as isolated system as well as keeping the working medium separate from the surroundings. The shape of the closed pipe forming the container could be of circular, flat or triangular cross-section. The heat pipe container should be strong enough to stand internal dimension and internal pressure in case of compression or bending. High thermal conductivity and formability, toughness, machinability and capacity for being easily soldered or welded are the expected properties for container material. [10]

b) Working Medium

The working medium of a heat pipe is the liquid contained within the tube or container and undergoes phase change from evaporation to condensation with repetitions. Its selection is important for the design and manufacture of a heat pipe. According to the working temperature range of the heat pipe a particular working fluid could be chosen. While choosing a working fluid, it is necessary to be careful 
whether the operating temperature range of the working fluid lies in the operating temperature range of the heat pipe. [10]

\subsection{Working Principle of a Gravitational Heat Pipe Under Experiment in this Project}

A metallic void structure namely container of the heat pipe is partially filled with a working fluid. A gravitational heat pipe without any wick structure has mainly two sections, an evaporator and a condenser. Using some external source of heat the working liquid is heated to its boiling point. This evaporation happens in the evaporator section which absorbs heat and uses it to convert working liquid to vapor, which expands to fill the entire internal space of heat pipe. The condenser is kept in direct contact with heat sink. The heat sink is mainly another pipe, also called header pipe, through which another liquid flows which takes away the heat from the vaporized working fluid of the heat pipe. After rejecting heat vaporized working fluid condensed back to liquid form. Then the working liquid returns to evaporator section and the cycle repeat itself. [11] Figure given below shows the operating principle of a gravitational heat pipe.

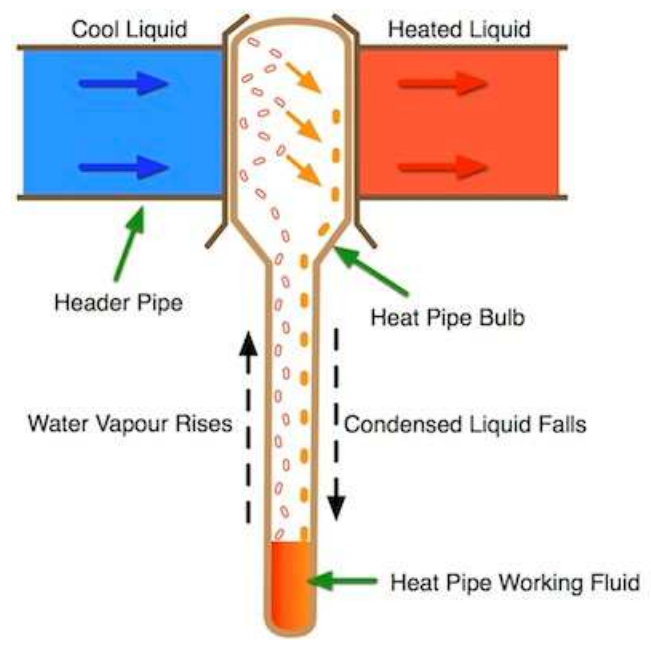

Figure 2. Operating principle of heat pipe.

\subsubsection{Scientific Exposition of Operating Principle of Liquid inside a Heat Pipe}

For a liquid their boiling point is related to the atmospheric pressure. The lower the atmospheric pressure the lower will be the temperature for the liquid to get to its boiling point as with the decrease in atmospheric pressure the vapor pressure of the liquid also decreases. As the heat pipe is a metallic container with vacuum the fluid inside it boils very easily at a much notable lower temperature than its boiling point.

\subsubsection{Limitations of Heat Pipe}

When heated above a certain temperature, all of the working fluid in the heat pipe vaporizes and the condensation process ceases. In such conditions, the heat pipe's thermal conductivity is effectively reduced to the heat conduction properties of its solid metal casing alone. As most heat pipes are constructed of copper, an overheated heat pipe will generally continue to conduct heat at around $1 / 80$ of the original heat flux via conduction only rather than evaporation. In addition, below a certain temperature, the working fluid will not undergo phase change, and the thermal conductivity is reduced to that of the solid metal casing. One of the key criteria for selecting a working fluid is the desired operational temperature range of the application. The lower temperature limit typically occurs a few degrees above the freezing point of the working fluid. [12]

\section{Design of the Prototype and Construction of the Hybrid Heat Pipe Solar Collector with Absorber Plate and Experimental Proceedings}

\subsection{Design of the Hybrid Heat Pipe Solar Collector}

The heat pipe solar collector in this project contains four major parts. They are heat pipe, a metallic header pipe, a manifold and an absorber plate.

\subsubsection{Heat Pipe}

Hollow copper pipes of $3 / 8$ inch diameter and of 2 feet length were used as heat pipes. Total 6 heat pipes were used for the collector.

\subsubsection{Header Pipe}

The header pipe performs the function of heat sink. It contains the condensers where the vaporized working liquid of the heat pipe rejects heat. A hollow copper pipe of $1 / 2$ inch diameter was used as header pipe. The header pipe was connected to the heat pipe by brazing.

\subsubsection{Manifold}

The manifold provides insulation to the header pipe. It is mainly a casing that holds the insulation. A GP (Galvanized Plain) steel casing was used for this purpose. The manifold was packed with glass wool insulation to withstand the temperature of up to $482^{\circ} \mathrm{F}$ and silicone rubber sealing was used.

\subsubsection{Absorber Plate}

Absorber plates are used for increasing the surface area exposed to sunlight. They are placed in touch with the heat pipes. A steel plate with black coating was used for this purpose

\subsection{Factors Analyzed in the Design of the Project}

\subsubsection{Selection of Working Liquid in the Heat Pipe}

Recommended features of working fluid refer to the compatibility with the heat pipe container, good thermal stability, vapor pressure in the operating temperature range, high surface tension, low viscosity of the liquid and vapor phase, high thermal conductivity, high latent heat of vaporization, acceptable melting point and solidification point. [13] For the structure in this paper acetone was chosen as working fluid in heat pipe. Acetone boils at $56^{\circ} \mathrm{C}$ under atmospheric pressure. Under vacuum acetone boils off at about $7^{\circ} \mathrm{C}$. Table 1 shows the boiling point of acetone at 
different pressures less than atmospheric pressure. [14]

Table 1. Boiling point of acetone under distinct pressures.

\begin{tabular}{ll}
\hline Boiling Point $\left({ }^{\circ} \mathbf{C}\right)$ & Pressure $(\mathbf{a t m})$ \\
\hline-31.1 & 0.0132 \\
-9.4 & 0.053 \\
-2 & 0.0789 \\
7.7 & 0.132 \\
22.7 & 0.263 \\
\hline
\end{tabular}

\subsubsection{Shell Material Selection for Heat Pipe}

Selection of the heat pipe wall or shell material depends on its chemical compatibility with the working fluid to prevent corrosion or chemical reaction between the fluid and the heat pipe wall material. Chemical compatibility problem between the working fluid and wall material within a heat pipe can create a chemical reaction that produces a non-condensable gas causing operational failure. Copper was chosen for shell material of the heat pipe in this study. Following table shows compatible materials for some commonly used working fluids. [15]

Table 2. Suitable materials as to working fluids.

\begin{tabular}{ll}
\hline Working fluid & Compatible materials \\
\hline Water & Stainless steel, copper, nickel \\
Methanol & Stainless steel, iron, nickel, copper \\
Acetone & Aluminum, Stainless steel, Copper, nickel \\
Freon-11 & Aluminum \\
Freon-21 & Aluminum, iron \\
Freon-113 & Aluminum \\
\hline
\end{tabular}

\subsubsection{Absorber Plate Materials}

Required properties for absorber material are high thermal conductivity, necessary tensile and compressive strength and good corrosion. Copper, aluminum, steel and various thermo plastics are generally used for this purpose. Though copper is preferred of all due to its high conductivity and resistance to corrosion because of its high cost steel was used instead in this project. Properties of some materials for absorber plates are shown in the table below.

Table 3. Properties of absorber plate materials.

\begin{tabular}{llll}
\hline Material & $\begin{array}{l}\text { Density } \\
\left(\mathbf{k g} / \mathbf{m}^{\mathbf{3}}\right)\end{array}$ & $\begin{array}{l}\text { Specific heat } \\
\left(\mathbf{k J} / \mathbf{k g}^{\circ} \mathbf{C}\right)\end{array}$ & $\begin{array}{l}\text { Thermal conductivity } \\
\left(\mathbf{W} / \mathbf{m}^{\circ} \mathbf{C}\right)\end{array}$ \\
\hline Aluminum & 2707 & 0.996 & 204 \\
Iron & 7897 & 0.452 & 73 \\
Steel & 7833 & 0.465 & 54 \\
Copper & 8954 & 0.385 & 386 \\
\hline
\end{tabular}

\subsubsection{Insulation}

Low thermal conductivity and stability at high temperature are key properties of an insulating material. Insulating materials are glass wool, crown white wool, crown bonded 150 , calcium silicate, foam etc. Glass wool was used as insulating material filled within the manifold in this paper work.

\subsection{Fabrication of the Heat Pipe Solar Collector}

\subsubsection{Layout of the Structure}

For the establishment of the heat pipe solar collector the collection of the following essential elements were first reviewed.

a) 6 hollow Copper pipes of 3/8 inch diameter and 2 feet length

b) Tiny solid copper blocks to enclose the pipe ends

c) 1 inch diameter and 2 feet length copper pipe as the header pipe

d) GP (Galvanized Plain) steel with area of $5.25 \times 20$ square inch as calculated for the manifold

e) Steel plate of $21.5 \times 26.5$ square inch after sizing as absorber plate

f) Borosilicate glass plate as cover plate

g) Black paint for coating

\subsubsection{Hypothetical Layout of Hybrid Heat Pipe Solar Collector}

A hypothetical model of hybrid heat pipe solar collector was sketched.

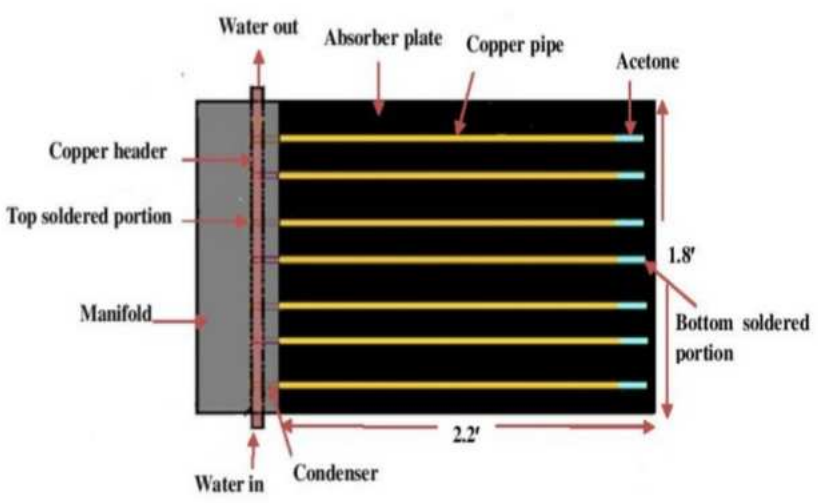

Figure 3. Hypothetical layout of hybrid heat pipe solar collector.

\subsubsection{Construction of Solar Collector}

i. Making of Heat Pipes

First of all six hollow copper pipes of $3 / 8$ inch diameter and 2 feet length were collected (Figure 4). A tiny solid copper block was used to close bottom end the hollow copper pipe containing acetone (Figure 5). The tiny solid block was attached to the bottom of the copper pipe by brazing (Figure 6). Six 1/2 inch diameter small hollow Copper pipes were collected as condensers (Figure 7). They were positioned within the header pipe and connected to the top of the heat pipes as condensers. Six holes were drilled on 1 inch diameter copper pipe used as the header pipe for inserting the condensers on the top of the $3 / 8$ inch copper pipe (Figure 8 ). Then the condensers were joined to the $3 / 8$ inch copper heat pipe by brazing (Figure 9). Figure 10 shows the way the top end of the condenser was covered. Then the copper pipes were brazed to the header (Figure 11). After that about $8 \mathrm{ml}$ of acetone was injected in the copper tube (Figure 12). Heat was applied externally at the lower end of the heat pipe (Figure 13). At first the acetone inside the copper tube started to boil. With the raise in the applied heat acetone began to vaporize. When the acetone was vaporized fully and just started off coming out of the heat pipe the top end was sealed by soldering (Figure 14). All the heat pipes were made in the 
same way.

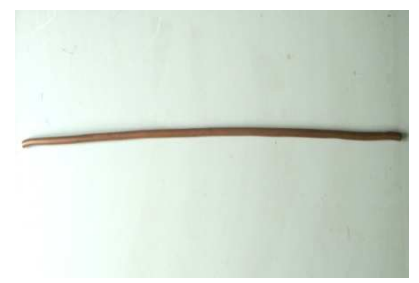

Figure 4. 3/8 inch copper pipe block.

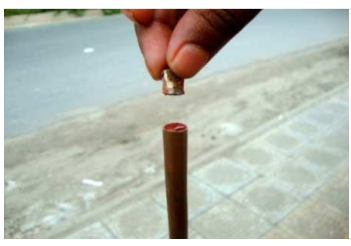

Figure 5. Tiny solid Copper to hollow copper pipe.

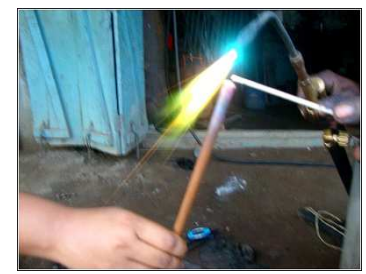

Figure 6. Brazing the block.

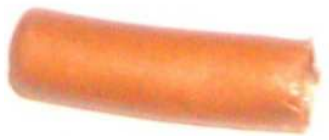

Figure 7. Condenser drilling.

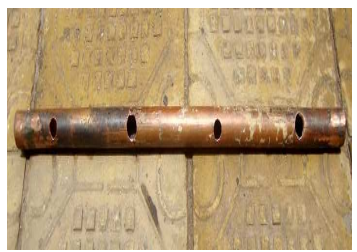

Figure 8. Header pipe under to condenser

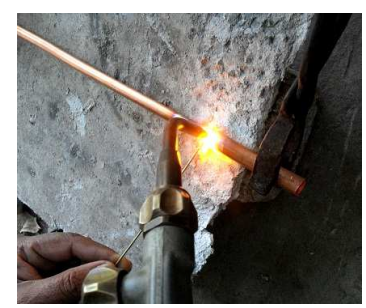

Figure 9. Brazing copper pipe.

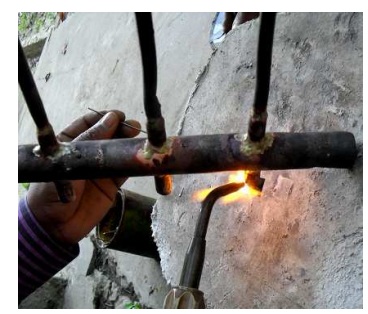

Figure 10. Covering top of the condenser.

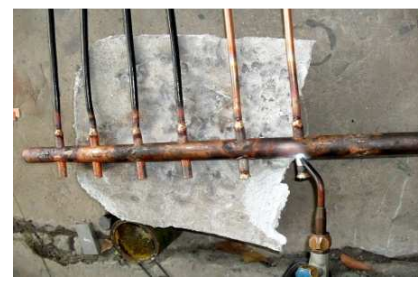

Figure 11. Attaching Copper pipes to the header pipe.

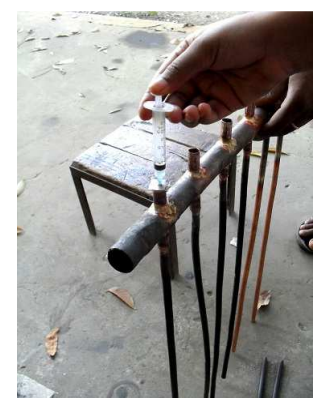

Figure 12. Injecting Acetone

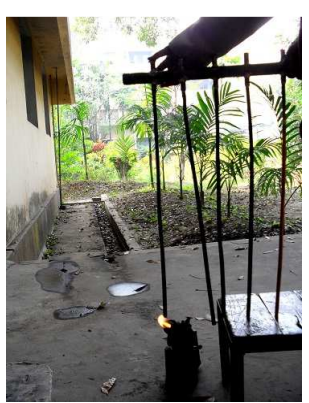

Figure 13. Applying heat.

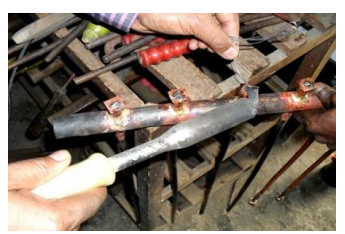

Figure 14. Soldering.

ii. Insulation and Frame Making for the Complete Set Up of the Heat Pipe Solar Collector

All of the heat pipes were inserted into the manifold (Figure 15) and was insulated using glass wool (Figure 16). Via cutter machine steel plate was sized according to the dimensions to design the frame that will carry the heat pipes and so the absorber plate (Figure 17). Glass plate was used as cover plate fitted within a frame (Figure 18) and to sheath the main frame (Figure 19). Finally the absorber plate touching the heat pipes were placed within the main frame box and the structure was completed (Figure 20).

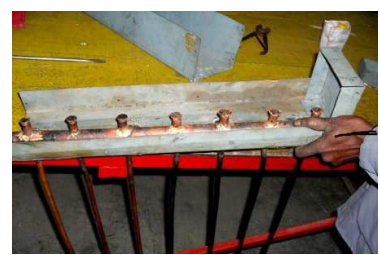

Figure 15. Inserting heat pipes to the manifold. 


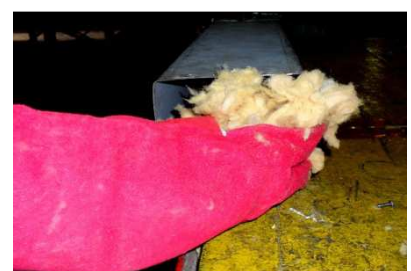

Figure 16. Glass wool insulation.

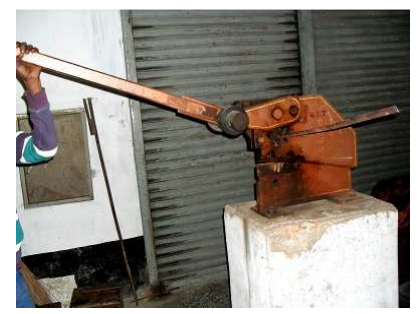

Figure 17. Processing steel plate in shear machine.

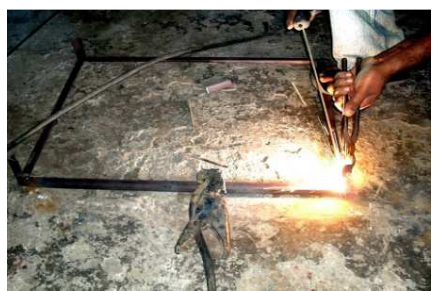

Figure 18. Frame for glass Cover.

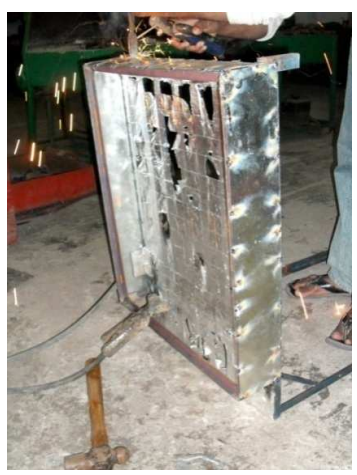

Figure 19. Main Frame.

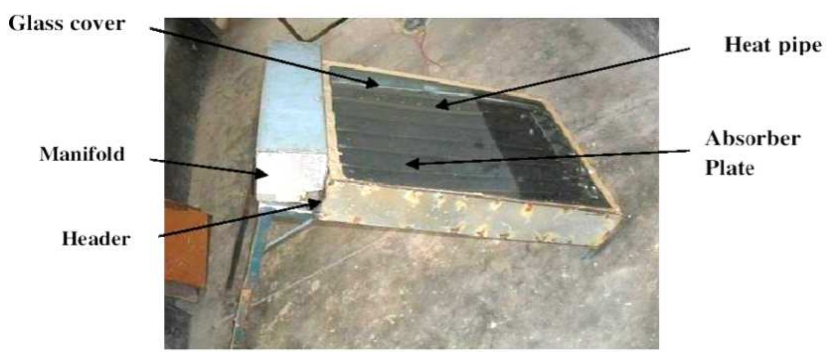

Figure 20. Complete set up of hybrid heat pipe solar collector with an absorber plate.

\subsection{Experimental Procedure}

\subsubsection{Methodology}

First of all the heat pipe solar collector was placed at a sunny place. Then water was supplied through one end of the header pipe. The inlet temperature of the collector was measured using a thermometer. Mass flow rate was measured using a $100 \mathrm{ml}$ measuring cylinder. The time was recorded by a stop watch until the measured cylinder was filled. Then dividing $100 \mathrm{ml}$ by the recorded time mass fow rate was obtained. After that through an interval of 30 minute the outlet temperature of the collector was measured using thermometer. In this way several readings were taken for few days in the month of November with slight streaching in the month of December. The solar intensity on the days of experiment was measured by solar photovoltaic trainer. The intensity was measured at the same time when the temperature of outgoing water from collector was measured.

\subsubsection{Data Collection}

Before getting on with processing data, the stage goes on is data collection, which falls within the experimental processes. By testing for quite a long period of time, a large number of data were collected, but not all of the data were completely correct due to error of human operations as well as error of the instruments. Data collected with calculated efficiencies are grouped in the tables bellow.

Table 4. Data table for hybrid heat pipe solar collector on 17-11-18.

\begin{tabular}{|c|c|c|c|c|c|c|}
\hline Time & $\begin{array}{l}\text { Inlet Temperature } \\
\mathrm{T}_{\mathrm{i}}\left({ }^{\circ} \mathrm{C}\right)\end{array}$ & $\begin{array}{l}\text { Outlet temperature } \\
\mathrm{T}_{0}\left({ }^{\circ} \mathrm{C}\right)\end{array}$ & $\begin{array}{l}\text { Temperature } \\
\text { Difference } \Delta \mathrm{T}\left({ }^{\circ} \mathbf{C}\right)\end{array}$ & $\begin{array}{l}\text { Mass Flow Rate, } \\
\dot{\mathrm{m}} \mathrm{Kg} / \mathrm{s}) \times 10^{-3}\end{array}$ & $\begin{array}{l}\text { Solar Intensity, } \\
\text { I }\left(\mathrm{W} / \mathbf{m}^{2}\right)\end{array}$ & $\begin{array}{l}\text { Efficiency, } \\
\eta(\%)\end{array}$ \\
\hline 12.15PM-12.45PM & 19.2 & 30.2 & 11 & 2.1 & 961.8 & 27.44 \\
\hline 12.45PM-1.15PM & 18.9 & 29.6 & 10.7 & 2.1 & 955.9 & 26.86 \\
\hline 1.15PM-1.45PM & 18.5 & 29 & 10.5 & 2.1 & 945.9 & 26.64 \\
\hline 1.45PM-2.15PM & 18.1 & 28.1 & 10 & 2.1 & 931.1 & 25.77 \\
\hline 2.15PM-2.45PM & 17.3 & 27.1 & 9.8 & 2.1 & 909.55 & 25.85 \\
\hline
\end{tabular}

Table 5. Data table for hybrid heat pipe solar collector on 22-11-18.

\begin{tabular}{lllllll}
\hline Time & $\begin{array}{l}\text { Inlet Temperature } \\
\mathbf{T}_{\mathbf{i}}\left({ }^{\circ} \mathbf{C}\right)\end{array}$ & $\begin{array}{l}\text { Outlet Temperature } \\
\mathbf{T}_{\mathbf{0}}\left({ }^{\circ} \mathbf{C}\right)\end{array}$ & $\begin{array}{l}\text { Temperature } \\
\text { Difference } \Delta \mathbf{T}\left({ }^{\circ} \mathbf{C}\right)\end{array}$ & $\begin{array}{l}\text { Mass Flow Rate, } \\
\dot{\mathbf{m}}(\mathbf{K g} / \mathbf{s}) \times \mathbf{1 0} \mathbf{1 0}^{-3}\end{array}$ & $\begin{array}{l}\text { Solar Intensity, } \\
\mathbf{I}\left(\mathbf{W} / \mathbf{m}^{2}\right)\end{array}$ & $\begin{array}{l}\text { Efficiency, } \\
\boldsymbol{\eta}(\%)\end{array}$ \\
\hline $12.15 \mathrm{PM}-12.45 \mathrm{PM}$ & 19 & 31 & 12 & 1.92 & 963.4 & 27.33 \\
$12.45 \mathrm{PM}-1.15 \mathrm{PM}$ & 18.4 & 29.9 & 11.5 & 1.92 & 942.5 & 26.77 \\
$1.15 \mathrm{PM}-1.45 \mathrm{PM}$ & 18 & 29 & 11 & 1.92 & 939.5 & 25.69 \\
$1.45 \mathrm{PM}-2.15 \mathrm{PM}$ & 17.6 & 28 & 10.4 & 1.92 & 925.1 & 24.66 \\
$2.15 \mathrm{PM}-2.45 \mathrm{PM}$ & 17.1 & 28.1 & 10 & 1.92 & 905.8 & 24.22 \\
\hline
\end{tabular}


Table 6. Data table for hybrid heat pipe solar collector on 26-11-18.

\begin{tabular}{|c|c|c|c|c|c|c|}
\hline Time & $\begin{array}{l}\text { Inlet Temperature } \\
\mathrm{T}_{\mathrm{i}}\left({ }^{\circ} \mathrm{C}\right) \\
\end{array}$ & $\begin{array}{l}\text { Outlet Temperature } \\
\mathbf{T}_{\mathbf{0}}\left({ }^{\circ} \mathbf{C}\right)\end{array}$ & $\begin{array}{l}\text { Temperature } \\
\text { Difference } \Delta \mathbf{T}\left({ }^{\circ} \mathbf{C}\right)\end{array}$ & $\begin{array}{l}\text { Mass Flow Rate, } \\
\dot{\mathbf{m}}(\mathrm{Kg} / \mathrm{s}) \times 10^{-3}\end{array}$ & $\begin{array}{l}\text { Solar Intensity, } \\
\text { I }\left(\mathbf{W} / \mathbf{m}^{2}\right)\end{array}$ & $\begin{array}{l}\text { Efficiency, } \\
\eta(\%) \\
\end{array}$ \\
\hline 12.15PM-12.45PM & 19.1 & 30.3 & 11.2 & 1.88 & 960.1 & 25.06 \\
\hline 12.45PM-1.15PM & 18.6 & 29.4 & 10.8 & 1.88 & 944.8 & 24.56 \\
\hline 1.15PM-1.45PM & 18.3 & 28.8 & 10.5 & 1.88 & 936.1 & 24.09 \\
\hline 1.45PM-2.15PM & 18 & 28 & 10 & 1.88 & 925.4 & 23.21 \\
\hline 2.15PM-2.45PM & 17.8 & 27.6 & 9.8 & 1.88 & 910.1 & 23.13 \\
\hline
\end{tabular}

Table 7. Data table for hybrid heat pipe solar collector on 1-12-18

\begin{tabular}{|c|c|c|c|c|c|c|}
\hline Time & $\begin{array}{l}\text { Inlet Temperature } \\
\mathrm{T}_{\mathbf{i}}\left({ }^{\circ} \mathrm{C}\right)\end{array}$ & $\begin{array}{l}\text { Outlet Temperature } \\
\mathbf{T}_{0}\left({ }^{\circ} \mathrm{C}\right)\end{array}$ & $\begin{array}{l}\text { Temperature } \\
\text { Difference } \Delta T\left({ }^{\circ} \mathrm{C}\right)\end{array}$ & $\begin{array}{l}\text { Mass Flow Rate, } \\
\dot{\mathbf{m}}(\mathrm{Kg} / \mathrm{s}) \times 10^{-3}\end{array}$ & $\begin{array}{l}\text { Solar Intensity, } \\
\mathbf{I}\left(\mathbf{W} / \mathbf{m}^{2}\right)\end{array}$ & $\begin{array}{l}\text { Efficiency, } \\
\eta \%\end{array}$ \\
\hline 12.15PM-12.45PM & 18.6 & 29.4 & 10.8 & 1.85 & 962.1 & 23.73 \\
\hline 12.45PM-1.15PM & 18 & 28.5 & 10.5 & 1.85 & 950.4 & 23.35 \\
\hline 1.15PM-1.45PM & 17.9 & 28.2 & 10.3 & 1.85 & 941.7 & 23.12 \\
\hline 1.45PM-2.15PM & 17.6 & 27.4 & 9.8 & 1.85 & 930.3 & 22.3 \\
\hline 2.15PM-2.45PM & 17.2 & 26.7 & 9.5 & 1.85 & 915.8 & 21.9 \\
\hline
\end{tabular}

Table 8. Data table for hybrid heat pipe solar collector on 5-12-18.

\begin{tabular}{|c|c|c|c|c|c|c|}
\hline Time & $\begin{array}{l}\text { Inlet Temperature } \\
\mathbf{T}_{\mathbf{i}}\left({ }^{\circ} \mathrm{C}\right)\end{array}$ & $\begin{array}{l}\text { Outlet Temperature } \\
\mathbf{T}_{\mathbf{0}}\left({ }^{\circ} \mathrm{C}\right) \\
\end{array}$ & $\begin{array}{l}\text { Temperature } \\
\text { Difference } \triangle T\left({ }^{\circ} \mathbf{C}\right)\end{array}$ & $\begin{array}{l}\text { Mass Flow Rate, } \\
\dot{\mathbf{m}}(\mathrm{Kg} / \mathrm{s}) \times 10^{-3} \\
\end{array}$ & $\begin{array}{l}\text { Solar Intensity, } \\
\mathrm{I}\left(\mathrm{W} / \mathbf{m}^{2}\right)\end{array}$ & $\begin{array}{l}\text { Efficiency, } \\
\eta(\%)\end{array}$ \\
\hline 12.15PM-12.45PM & 18.5 & 30.3 & 11.8 & 1.88 & 958.8 & 26.44 \\
\hline 12.45PM-1.15PM & 18.2 & 29.5 & $11 . .3$ & 1.88 & 944.7 & 25.7 \\
\hline 1.15PM-1.45PM & 17.5 & 28.3 & 10.8 & 1.88 & 937.1 & 24.76 \\
\hline 1.45PM-2.15PM & 17.2 & 27.7 & 10.5 & 1.88 & 923.5 & 24.42 \\
\hline 2.15PM-2.45PM & 17 & 26.8 & 10.08 & 1.88 & 908.3 & 23.8 \\
\hline
\end{tabular}

\subsubsection{Data Processing Equations and Calculations}

In oder to evaluate the efficiency of the heat pipe solar collector some very common mathematical approaches were taken.

i. Input Power Calculation

The area (A) of the collector, consuming solar heat, using measured dimentions,

$$
\mathrm{A}=\text { width } \times \text { height }=21.5^{\prime \prime} \times 26.5^{\prime \prime}=0.3675 \mathrm{~m}^{2}(1)
$$

Solar intensity (I) was taken using photovoltaic trainer and it varied during different periods of a day with sun position to quantify input solar power.

Equation for Input Power

$$
\mathrm{Q}_{\mathrm{i}}=\operatorname{Area}(\mathrm{A}) \times \text { Solar Intensity }(\mathrm{I})
$$

Referring to Table 4, the solar intensity in between 12.15PM-12.45PM was $961.8 \mathrm{~W} / \mathrm{m}^{2}$

Referring to Table 4 , in between 12.15PM-12.45PM, Input power $=0.3675 \mathrm{~m}^{2} \times 961.8 \mathrm{~W} / \mathrm{m}^{2}=353.46 \mathrm{~W}$

ii. Output Power Calculation

For heat pipe solar collector the output power is the heat delivered by the water flowing out of the header pipe as well as heat succumbed by the working liquid within the heat pipe.

Expression for Output heat,

$$
\mathrm{Q}_{\mathrm{o}}=\dot{\mathrm{m}} \mathrm{S} \triangle \mathrm{T}_{\mathrm{o}}
$$

Where, $\dot{\mathrm{m}}=$ mass flow rate, $\mathrm{kg} / \mathrm{sec}$

$\mathrm{S}=$ Specific heat of water $=4200 \mathrm{~kJ} / \mathrm{kg} . \mathrm{K}$

$\triangle \mathrm{T}_{\mathrm{o}}=$ Temperature difference in Kelvin $(\mathrm{K})$

Referring to Table 4 , in between $12.15 \mathrm{PM}-12.45 \mathrm{PM}$, the temperature difference $\triangle T_{0}$ was measured to be $11 \mathrm{~K}$

Hence, referring to table 4 , in between 12.15PM-12.45PM,

Output heat, $\mathrm{Q}_{\mathrm{o}}=\dot{\mathrm{m}} \mathrm{S} \triangle \mathrm{T}$

$=2.1 \times 10^{-3} \mathrm{~kg} / \mathrm{s} \times 4200 \mathrm{~kJ} / \mathrm{kg} . \mathrm{K} \times 11 \mathrm{~K}$

$=97.02 \mathrm{~W}$

iii. Efficiency Calculation

Equation for overall efficiency of heat pipe solar collector,

$$
\eta=\frac{\text { output power }}{\text { input power }}
$$

Referring to Table 4, in between 12.15PM-12.45PM,

Efficiency $=$ output power $\left(\mathrm{Q}_{\mathrm{o}}\right) /$ input power $\left(\mathrm{Q}_{\mathrm{i}}\right)$ $=97.02 / 353.46=0.2744=27.44 \%$

\section{Results and Discussions}

\subsection{Variation of Efiiciency with Time and Solar Intensity}

After collectiong several data efficiencies were plotted against time as given below

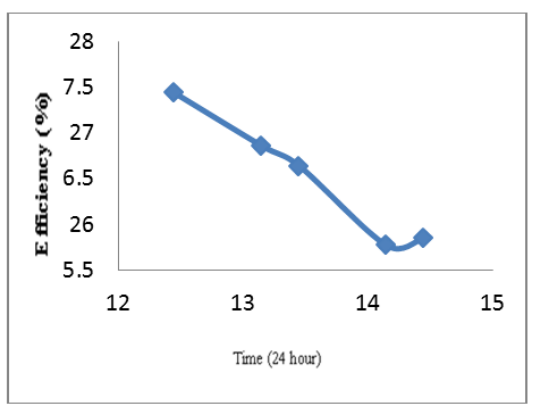

Figure 21. Efficiency Vs Time curve referring to table 4. 
From figure 21 referring to table 4 , the highest efficiency of the heat pipe solar collector is $27.44 \%$ at $12.45 \mathrm{PM}$ with solar intensity $961.8 \mathrm{~W} / \mathrm{m}^{2}$ and mass flow rate $2.1 \times 10^{-3} \mathrm{~kg} / \mathrm{s}$. The data were taken in the month of November when the solar intensity is much less than summer days. It is seen from the curve that the efficiency decreases with time as well as the solar intensity with a slight deviation at the edge point where the efficiency is slightly increased.

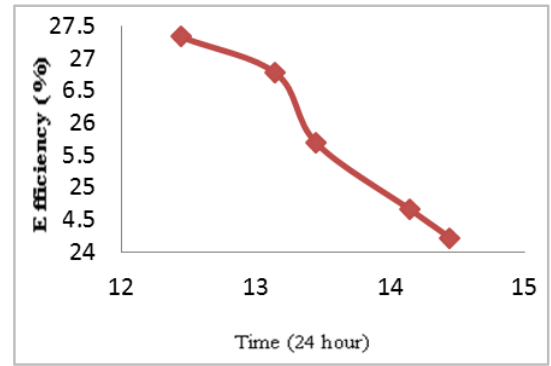

Figure 22. Efficiency Vs Time curve referring to table 5.

From figure 22 referring to table 5, the highest efficiency of the heat pipe solar collector is $27.33 \%$ at $12.45 \mathrm{PM}$ with solar intensity $963.4 \mathrm{~W} / \mathrm{m}^{2}$ and mass flow rate $1.92 \times 10^{-3} \mathrm{Kg} / \mathrm{s}$, with data taken five days after the first data were taken. It is seen from the curve that the efficiency decreases steadily with time as well as the solar intensity.

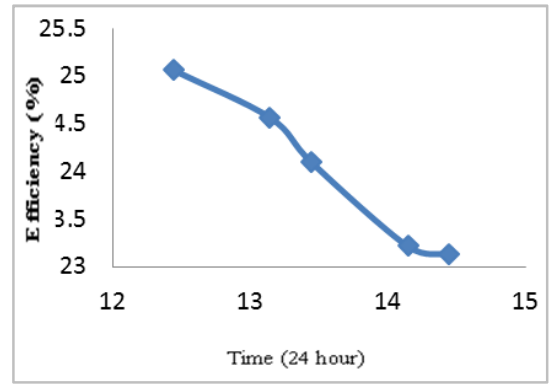

Figure 23. Efficiency Vs Time curve referring to table 6.

From figure 23 referring to table 6 , the efficiency decreases with time as well as with the solar intensity. Calculated highest efficiency was $25.06 \%$ with solar intensity $960.1 \mathrm{~W} / \mathrm{m}^{2}$ with mass flow rate $1.88 \times 10^{-3} \mathrm{Kg} / \mathrm{s}$. Slope of the curve is slightly steep among the intermediate data whereas the difference between the last two efficiencies is quite low and so the curve is nearly linear at the very end and this is caused by small difference in temperature.

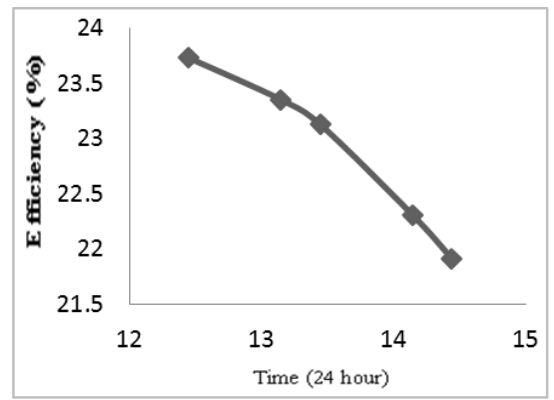

Figure 24. Efficiency Vs Time curve referring to table 7.
From figure 24 referring to table 7 , the efficiency decreases with time as well as with the solar intensity. There are no irregular deviations among the data and the curve shape is very orderly. Highest efficiency was found to be $23.73 \%$ with solar intensity $962.1 \mathrm{~W} / \mathrm{m}^{2}$. The mass flow rate was $1.85 \times 10^{-3} \mathrm{Kg} / \mathrm{s}$. The efficiency found was the lowest calculated efficiency over the total efficiencies computed during the experiment.

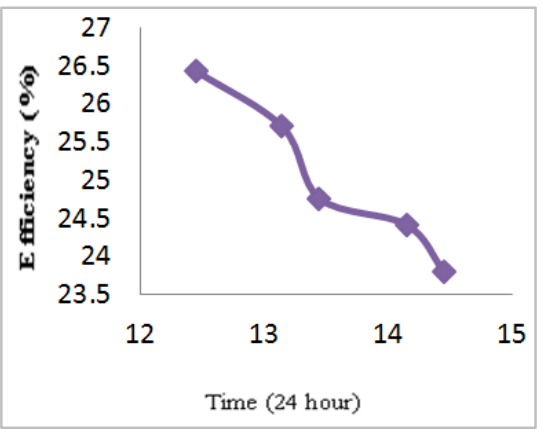

Figure 25. Efficiency Vs Time curve referring to table 8 .

From figure 25 referring to table 8 , the curve shape is slightly curvy. This is due to the fact that the efficiency following the highest efficiency is quite less than the previous one. Highest efficiency was calculated to be $26.44 \%$ with solar intensity of about $958.8 \mathrm{~W} / \mathrm{m}^{2}$ and mass flow rate $1.88 \times 10^{-3} \mathrm{Kg} / \mathrm{s}$. Efficiency decreases with time as well as with the solar intensity.

\subsection{Bar Diagram Comparing Efficiency with Solar intensity}

A bar chart was plotted with peak efficiencies computed from consecutive readings along with the associated solar intensity as shown in the figure below.

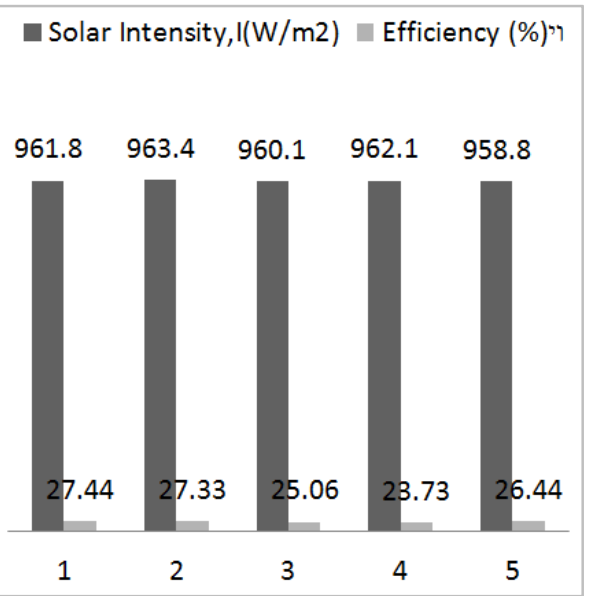

Figure 26. Solar collector efficiency against solar intensity.

Referring to figure 26, the highest efficiency for heat pipe solar collector is $27.44 \%$ with solar intensity of $961.8 \mathrm{~W} / \mathrm{m}^{2}$. With the highest solar intensity $963.4 \mathrm{~W} / \mathrm{m}^{2}$, the collector efficiency goes with $27.33 \%$ slightly less than the highest efficiency. Efficiencies of the collector did not vary very 
sharply with the solar intensity due to other factors like heat loss to the surroundings by convection and radiation. For a certain day the highest efficiency always falls within the highest solar intensity period. For set of days of data recording highest solar collector efficiency was not fixed with the peak solar intensity of the grouped days.

\subsection{Comparission and Perusal}

As the project under discussion was completely new and unaltered in the working background, obtained efficiency was compared with some other types of collectors, designed and examined under research projects at Rajshahi University of Engineering and Technology.

a) Comparison with a Concentric Parabolic Solar Collector

Under the thesis project named, Design Construction and Performance Test of a Concentric Parabolic Solar Collector, a parabolic solar collector was fabricated and its efficiency was evaluated. Highest calculated efficiency of that collector was $21.1 \%$ in the month of April with water as working medium. [16] Where efficiency of the heat pipe solar collector is $27.33 \%$ with much lower solar intensity in the month of November. The gain in efficiency is mainly due to the reduction in heat loss in heat pipe solar collector. Referring to table 4, highest efficiency of hybrid heat pipe solar collector along with other calculated efficiencies was compared with the highest efficiency for concentric parabolic solar collector as shown in the following figure.

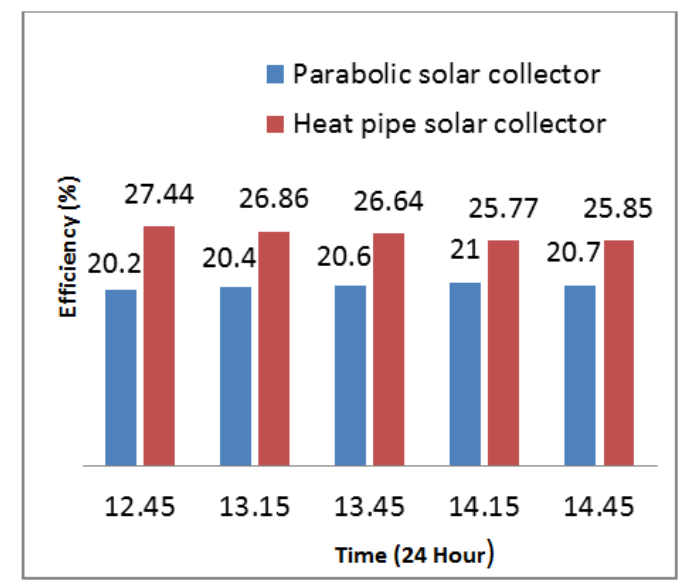

Figure 27. Efficiency of parabolic and heat pipe solar collector against time.

b) Comparison with solar water heater

Under the thesis project named, Design Construction and Performance Test of a solar water heater, efficiency of a solar water heater was evaluated. In the month of December the highest efficiency was $21.07 \%$ where heat pipe solar collector provides $26.44 \%$ efficiency under the same month. [17] Referring to table 8, calculated efficiencies of hybrid heat pipe solar collector were plotted against the calculated efficiencies of solar water heater, for which data were taken in the month of December, as shown in the figure given below.

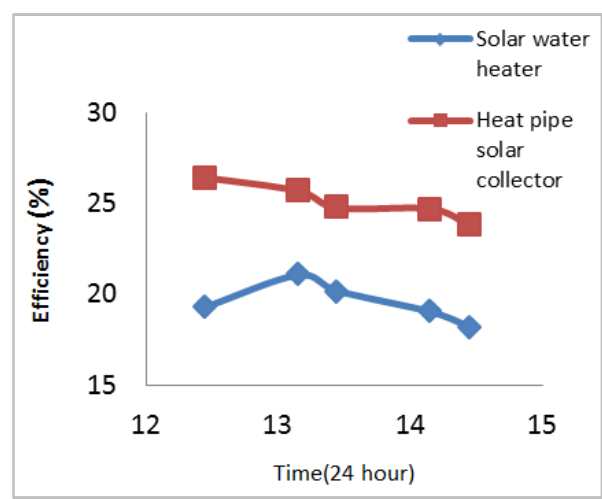

Figure 28. Efficiency of solar water heater and heat pipe solar collector against time.

\section{Concluding Remark}

This paper work sets forth with the degin and estublishment of a hybrid heat pipe solar collector which is utterly an unorthodrox project as well as allocation of the experimental data. Main hazard during the accomplicement of this project was starting off with the formation of proper vacuum within heat pipe and the construction of the entire solar collector in a cost effective way, that was also far out in the working baground of the project. As vacuum containted within the heat pipe is the firm module of its structure, its creation went through several difficulties such as sealing problems, selection of woring materials. Though, the very ruling point of this project work is conserned with the rectification of the structure of the heat pipe solar collector alongwith its efficincy. In this study the performance of the heat pipe solar collector was observed and analysed. The highest effieiency did not fall with the highest solar intensity because of heat loss. This paper work can lead to the construction of much more effective unprecedented hybrid heat pipe solar collector with more atriculate formation of heat pipe in an economical way.

\section{References}

[1] U. Dholakiya. A Review on Two Phase Thermosyphon Heat Transfer: a Case Study on Solar Evacuated Tube Water Heater. Volume: 2, Issue: 5, May 2013, ISSN No 2277.

[2] Dr. F. Mahjouri. Vacuum Tube Liquid Vapor (Heat-Pipe) Collectors www.thermothchs.com.

[3] Supplement 16, Environmental management of refrigeration equipment. Technical supplement to WHO Technical Report Series, No. 961, 2011 May 2015 Annex 9: Model guidance for the storage and transport of time- and temperature-sensitive pharmaceutical products, May 2015.

[4] Air Quality and Ductless Systems, Conditioned air of Carolina $\mathrm{http}: / /$ conditionedairofcarolina.com/additionalservices?fbclid=IwAR0Q4yMuFvAbnpAYo6YXX_C6wpmSuEP5MEWOtSt0UWosBH71Bkyd4u1Tsc

[5] M. A. Khan, Md. Shamsuddoha, Asif Hasan. Climate Change mitigation approaches in Bangladesh. Journal of sustainable development. DOI: $10.5539 /$ jsd.v6n7p59 
[6] Heat pipe definition from PC Magazine Encyclopediahttps://www.pcmag.com/encyclopedia/term/441 92/heat-pipe

[7] Vijaykumar. P, M. E, Sajairaj. S, Santhoshkumar. R, "Review on conventional, modern heat pipes and its applications", October -2016, Volume: 03ISSUE: 10, E-ISSN: 2395-0056

[8] Fabian Korn. Heat pipes and its applications. Project report. 2008 MVK160 Heat and Mass Transport. May 07, 2008.

[9] Cernecky J, Koniar J, Brodnianska Z. The effect of heat transfer area roughness on heat transfer enhancement by forced convection. Journal of Heat Transfer. April 2014; 136 (4) Article number 4025920

[10] Patrik Nemec, Porous Structures in Heat Pipes, December 20th 2017, Chapter 7, DOI: 10.5772/intechopen.71763

[11] Indira A Mhaisne, P. B. Borade, S. V. Mohitwar, Dr. A. A. Pawar, Dr. R. N. Panchal. Experimental Investigation Of Copper Sintered Heat Pipe Flow For Power Electronic Cooling by Vortex. OSR Journal of Mechanical and Civil Engineering (IOSR-JMCE), PP 50-54, e-ISSN: 2278-1684, pISSN: $2320-334 \mathrm{X}$
[12] B. Naga Murali, Kudumala Govardhan reddy, P. Kranthi Kuma]. Design, Analysis and Fabricaion of heat pipe. International Journal of Research in aeronautical and mechanical engineering. ISSN (ONLINE): 2321-3051. Vol. 3 September 2015. Pgs 1-9

[13] Swanson LW. Kreith F, editor. Heat Pipe, Heat and Mass Transfer, Mechanical Engineering Handbook. Boca Raton: CRC Press LLC; 1999

[14] Acetone Vapor pressure vs. boiling point, Chemical plant design \& operations Forum https://www.engtips.com/viewthread.cfm?qid=322387,

[15] Per Wallin. Project ReportMVK160. Heat and Mass Transfer. May 7, 2012.

[16] Faysal Hasan Razu, T. M. Jakir Hossain A Project Report on Design Construction and Performance Study of a Concentric Parabolic Solar Collector. Rajshai University of Engineering and Technology. April 2010.

[17] Nur-E-Fatima, Naima Akhter. A Project Report on Design, Construction and Performance Test of a Solar Water Heater. Rajshai University of Engineering and Technology March 2008 . 